\title{
SCHEDULED AUTOLOGOUS BLOOD DONATION AT THE TIME OF CARDIAC CATHETERIZATION IN INFANTS AND CHILDREN
}

\author{
Kazuaki Fukahara, MD, ${ }^{a}$ Arata Murakami, MD, ${ }^{\text {a }}$ Tetsuyuki Ueda, MD, ${ }^{\text {a }}$ Yoshinori Doki, MD, ${ }^{\text {a }}$ \\ Shinichi Tsubata, MD, ${ }^{b}$ Fukiko Ichida, MD, ${ }^{b}$ and Takuro Misaki, MD, ${ }^{a}$ Toyama, Japan
}

Preoperative autologous blood donation is commonly performed to avoid homologous blood transfusion during cardiac operations in adult patients. ${ }^{1}$ However, autologous blood donation for children is hampered by technical problems including lack of an adequate blood collection system and acute anemia after blood collection. Given the life span of children, it is most important to avoid the complications of homologous transfusion. ${ }^{2}$ We describe a technique of scheduled autologous blood donation during preoperative cardiac catheterization and examine the efficacy and safety of this method for use in infants and children.

Technique. Cardiac catheterization was performed about 2 weeks before elective operations in infants and children weighing at least $5 \mathrm{~kg}$. Autologous blood donation was performed in patients with a hematocrit value of $33 \%$ or more and a hemoglobin value of $11 \mathrm{gm} / \mathrm{dl}$ or more. Sedation was achieved with thiopental sodium and local anesthesia was achieved with lidocaine hydrochloride. Sheaths were inserted into the femoral artery and vein. After hemodynamic measurements, but before contrast angiography, $10 \mathrm{ml} / \mathrm{kg}$ of blood was collected via the arterial sheath. The same volume of lactated Ringer's solution was infused at the same rate through the venous sheath.

Collected blood was stored as packed red cells and plasma or as whole blood. Blood erythropoietin concentrations were measured before and after blood collection, and recombinant human erythropoietin $(100 \mathrm{U} / \mathrm{kg})$ was administered intravenously to acyanotic patients on the first and seventh days after blood collection. Cyanotic patients were not treated with recombinant human erythropoietin. Each patient was given ferrous sulfate $(2 \mathrm{mg}$ / $\mathrm{kg}$ ) orally every day.

Results. From October 1995 through September 1997, preoperative autologous blood donation was performed in 27 children, including 13 infants (16 boys and 11 girls). Their ages ranged from 6 months to 6 years, 8 months (average $1.9 \pm 2.1$ years). Their body weights ranged from $5.8 \mathrm{~kg}$ to $20.2 \mathrm{~kg}$ (average $9.7 \pm 5.5 \mathrm{~kg}$ ). The patients

From the Departments of Surgery a and Pediatrics, ${ }^{\mathrm{b}}$ Toyama Medical and Pharmaceutical University, Toyama, Japan.

Received for publication March 24, 1997; accepted for publication April 16, 1997.

Address for reprints: Arata Murakami, MD, Department of Surgery, Toyama Medical and Pharmaceutical University, 2630, Sugitani, Toyama, 930-01, Japan.

J Thorac Cardiovasc Surg 1997;114:504-5

Copyright (C 1997 by Mosby-Year Book, Inc.

$0022-5223 / 97 \$ 5.00+0 \quad \mathbf{1 2 / 5 4 / 8 2 6 6 7}$ included 21 acyanotic patients (10 with ventricular septal defect, eight with atrial septal defect, two with congenital coronary artery fistula, and one with ventricular septal defect plus pulmonic stenosis) and six cyanotic patients (three with tetralogy of Fallot and one patient each with pulmonary atresia plus ventricular septal defect, pulmonary atresia with intact ventricular septum, and single ventricle with pulmonic stenosis). All cyanotic patients received Blalock-Taussig shunts. Surgery was postponed beyond the expiration date of the autologous blood preservation in two patients who had upper respiratory tract infections. The preserved blood was infused into the one patient who was not cyanotic. Of the 27 patients who underwent preoperative autologous blood donation, 25 underwent cardiac operations. The surgical method was anatomic radical operation for all of the patients except one with single ventricle and pulmonic stenosis, who underwent a bidirectional Glenn shunt with the use of cardiopulmonary bypass (CPB).

The period between donation and surgery was 5 to 21 days (average $15.4 \pm 5.6$ days). Autologous blood was used as priming volume for CPB in six patients, to support CPB in seven patients, and for infusion after discontinuation of CPB in 12 patients. No complications related to autologous blood donation, autologous transfusion, or recombinant human erythropoietin administration were observed.

Nineteen patients $(76 \%)$ underwent surgery without homologous blood transfusion. Of the 20 acyanotic patients, $17(85 \%)$ underwent surgery without homologous blood transfusion. However, three of the five cyanotic patients required homologous blood transfusion.

The blood erythropoietin concentration before autologous blood donation was $14.2 \pm 4.6 \mathrm{mU} / \mathrm{ml}$ in the acyanotic patients and $19.8 \pm 7.2 \mathrm{mU} / \mathrm{ml}$ in the cyanotic patients $(p<0.05)$. The rate of improvement in anemia from autologous blood collection until surgery was significantly higher in cyanotic patients than that in acyanotic patients $(0.19 \pm 0.08 \mathrm{gm} / \mathrm{dl}$ per day in the acyanotic patients and $0.25 \pm 0.13 \mathrm{gm} / \mathrm{dl}$ per day in the cyanotic patients, $p \leq 0.05$ ).

Comment. In our institution, four procedures are used to allow transfusion-free cardiac operations in infants and children: (1) preoperative autologous blood donation, (2) administration of recombinant human erythropoietin, ${ }^{3}(3)$ decreasing the priming volume for $C P B$, and (4) use of blood cell scavenger techniques in CPB. ${ }^{4} \mathrm{We}$ have developed a method of preoperative autologous blood donation at the time of cardiac catheterization in infants and children. The benefits of this technique include the fact that blood can be collected during complete sedation with minimal patient discomfort and that blood collection in 
the cardiac catheterization laboratory allows monitoring of hemodynamics.

In the present study, the combined use of autologous blood donation at cardiac catheterization and treatment with recombinant human erythropoietin in acyanotic patients resulted in a high percentage of transfusion-free operations. Therefore this method may be useful in preventing transfusion-transmitted diseases. In contrast, in cyanotic patients, the transfusion-free surgery rate was low despite high blood erythropoietin concentrations and high recovery rate from anemia after autologous bloodcollection until the operation. On the basis of our findings, the strategy for transfusion-free cardiac operations for cyanotic patients should be examined further.

\section{REFERENCES}

1. Sandrelli L, Pardini A, Lorusso R, Sala ML, Licenziati M, Alfieri O. Impact of autologous blood predonation on a comprehensive blood conservation program. Ann Thorac Surg 1995;59:730-5.

2. Dodd RY. The risk of transfusion-mediated infection. N Engl J Med 1992;327:419-20.

3. Tasaki T, Ohto H, Hashimoto C, Abe R, Saitoh A, Kikuchi S. Recombinant human erythropoietin for autologous blood donation: effects on perioperative red-blood-cell and serum erythropoietin production. Lancet 1992;339:773-5.

4. Magilligan DJ. Indication for ultrafiltration in the cardiac surgical patient. J Thorac Cardiovasc Surg 1985;89:183-9.

\title{
SUCCESSFUL BRIDGING TO CARDIAC TRANSPLANTATION IN A DYSTROPHIC INFANT WITH THE USE OF A NEW PARACORPOREAL PNEUMATIC PUMP
}

\author{
Michael Weyand, MD, ${ }^{a}$ Deniz Kececioglu, MD, ${ }^{\mathrm{b}}$ Christof Schmid, MD, ${ }^{\mathrm{a}}$ Hans G. Kehl, MD, ${ }^{\mathrm{b}}$ Rene Tandler, MD, ${ }^{\mathrm{a}}$ \\ Heinz Michael Loick, MD, ${ }^{\mathrm{c}}$ and Hans H. Scheld, MD, ${ }^{a}$ Meunster, Germany
}

During the past decade, treatment of end-stage cardiac failure in adult patients with different forms of paracorporeal or implantable mechanical assist devices used as bridges to transplantation has become routine in many centers throughout the world. Survival after bridging and consecutive heart transplantation is comparable with that of nonbridged recipients if mechanical assistance lasts long enough to allow complete recovery of secondary organ dysfunction. However, no such mechanical assist device was available for neonates and smaller infants because of size incompatibility until recently. ${ }^{1-3}$ We report on our first experience with the MEDOS HIA system (MEDOS GmbH, Steinfurth, Germany) as a bridge to cardiac transplantation in a dystrophic infant, followed by successful cardiac transplantation.

A female child weighing $3490 \mathrm{gm}$ was born on June 6 , 1996. Delivery (Apgar scores at 1, 5, and 10 minutes were 10 ) and the early postpartum period was uneventful. At the age of 9 weeks, however, the child began having fever, shortness of breath, and sinus tachycardia. A chest $\mathrm{x}$-ray film demonstrated right lower lobe infiltration suggestive

From the Departments of Cardiothoracic Surgery, ${ }^{\text {a }}$ Pediatric Cardiology, ${ }^{\mathrm{b}}$ and Anesthesia and Operative Intensive Care, ${ }^{\mathrm{c}}$ Westfaelische Wilhelms Universitaet Muenster, Muenster, Germany.

Address for reprints: Michael Weyand, MD, Westfaelische Wilhelms Universitaet Muenster, Albert Schweitzer Straße 33, 48129 Muenster, Germany.

J Thorac Cardiovasc Surg 1997;114:505-7

Copyright (C) 1997 by Mosby-Year Book, Inc.

$0022-5223 / 97 \$ 5.00+0 \quad \mathbf{1 2 / 5 4 / 8 2 0 9 4}$ of pneumonia but, more important, a silhouette of a huge heart. After referral to our institution, echocardiography confirmed massive enlargement of both ventricles. Left ventricular fractional shortening was calculated as $8 \%$. Because she was in New York Heart Association class III-IV, the child was treated with digitalis, diuretics, and supportive oxygen at first. However, as the child's condition deteriorated further, with weight loss despite hypercaloric feeding and requirement of intravenous dopamine and dopexamine, she was listed for cardiac transplantation. The diagnosis was dilative cardiomyopathy, because no evidence of viral myocarditis was obtained. After 5 months on the waiting list, the child (3400 gm) had two episodes of cardiovascular collapse necessitating external heart massage and high-dose catecholamine support, as well as intubation and mechanical ventilation. Because no donor heart was available, the decision was made to use the paracorporeal MEDOS HIA system. Normothermic extracorporeal circulation was established with the use of a single atrial cannula. The arterial cannula was inserted into the proximal part of the aortic arch, leaving the ascending aorta untouched for the assist device. With the heart beating, a right-angled $18 \mathrm{~F}$ venous cannula was placed into the left atrium via the intraatrial groove, secured by two purse-string sutures of 5-0 monofilament polypropylene. ${ }^{4,5}$ The cannula was tunneled below the right costal margin to exit the skin in the right epigastrium. The arterial $18 \mathrm{~F}$ cannula was connected to the ascending aorta via a $4 \mathrm{~mm}$ polytetrafluorethylene graft, which exited the skin in the left epigastrium. After meticulous deairing, both tubes were connected to the $10 \mathrm{ml}$ paracorporeal ventricle placed onto the abdominal wall. The air driveline was connected to the console, left ventricular assist 